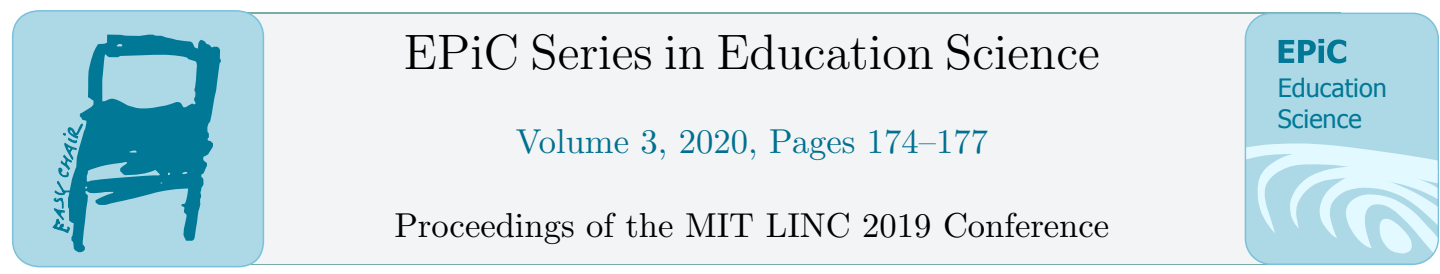

\title{
Teaching and Learning STEM in Peruvian High Schools with an Emphasis on Electrical Engineering and Computer Science
}

\author{
Arturo J. Miguel de Priego \\ STEM and EECS Academy \\ amiguel@pucp.edu.pe ${ }^{l}$
}

\begin{abstract}
This paper presents an ongoing work to involve Peruvian high school students in scientific research, engineering design, and mathematical modeling. It describes extracurricular workshops and classroom sessions to discover natural laws and solve real problems in local communities. The emphasis is on teaching and learning electrical engineering and computer science with an integrated approach to science, technology, engineering, and mathematics. The paper also introduces a projectbased and inquiry-based curriculum for high school, and GRISEL, a tool for virtual experiments with electronic design and computer programming.
\end{abstract}

\section{Introduction}

The integration of science, technology, engineering, and mathematics (STEM) is an effective way to achieve meaningful and lasting learning in the classroom, as people learn best when they construct interrelated concepts, apply them in different contexts, and reflect on their learning [1], [2]. However, the Peruvian education system gives few opportunities to transform classrooms in sceneries for real world learning [3].

Over eighteen years, extracurricular workshops have been developed to help high school students improve their performance in scientific research, engineering design and mathematical modeling. Computer programs and lesson guides were developed with emphasis on electrical engineering and computer science (EECS) [4]-[6]. This work was guided by a framework for engineering education [7] that combines other frameworks [8]-[10], free high-quality resources (books, courses, software), low-cost

\footnotetext{
${ }^{1}$ Personal email address. 
devices, and open hardware. The following sections describe a tool for teaching STEM topics; how students can discover logic circuits in extracurricular workshops; how to discover laws of physics, electronics, and robotics in math classes; some results obtained over the years, and the future work for this entrepreneurship.

\section{GRISEL}

GRISEL is an integrated set of computer programs designed to help students understand problems and designing solutions using STEM virtual experiments with multiple representations of circuits and algorithms. This tool facilitates the transition to more sophisticated programs for circuit design and programming. It provides interactive virtual sceneries to simulate the circuits and algorithms, and interactive tutorials to learn electronic design, computer programming, robotics, chemical reactions, kinematics, and math functions. Custom scenarios, tutorials, and circuits can be added by creating new $\mathrm{C}++$ classes. Previous versions are freely used in many Latin American and European high schools and universities.

\section{Discovering logic circuits in extracurricular workshops}

Students start logic circuit design by discovering the operation of a NAND gate using GRISEL and real hardware. They analyze special cases to find patterns, and design NAND-based and SSI circuits, including latches and flip-flops. Next, students analyze and design more complex circuits such as a water level controller and a stopwatch (figure 1), and build the actual circuits with TTL chips, FPGA devices, microcontrollers and typical interfaces.
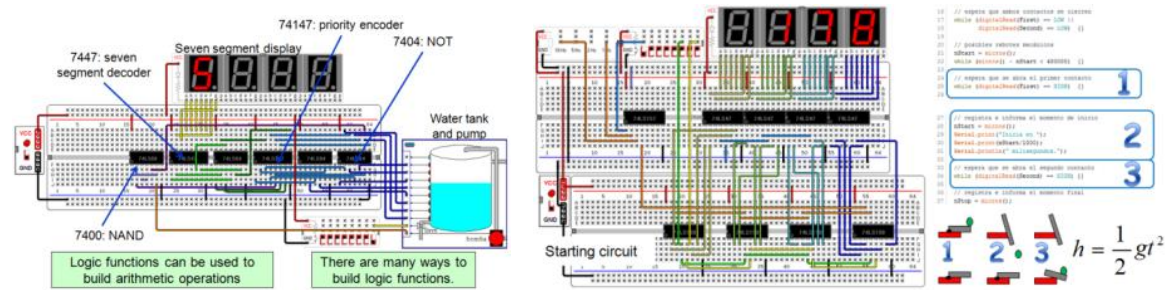

Figure 1. Circuits and programs.

In a design challenge, students build a prototype to calculate the acceleration of a mobile with initial speed. They have to find a mathematical formula and design the circuit and interfaces. To help students, an ASIC model shows how the circuit should function at the logical level, and modular blocks are provided to build a rapid prototype (Figure 2). Then, students develop both programmable and microcontroller logic solutions (using VHDL and C languages). At each step, students are helped to deal with important problems: signal adaptation, logic activation levels, circuit size versus performance, abstraction, implementation tools, modular design, hardware and software co-design, etc. Along the way, the teacher observes how students 
select, analyze and integrate circuits and algorithms to build systems and how they communicate their ideas. These observations are useful for designing new activities and customizing tools to reinforce student learning.
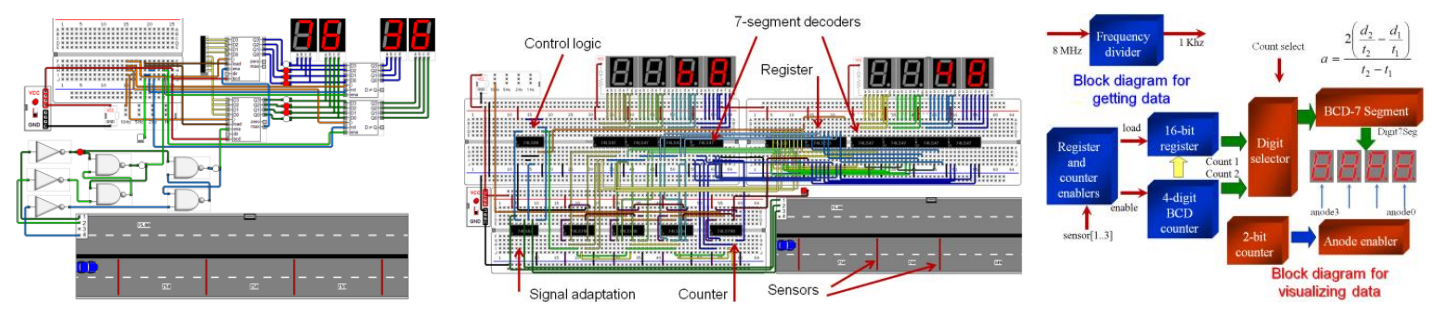

Figure 2. Building complex circuits.

\section{Discovering physics laws, electronics, and robotics in the math classroom}

A math lesson was designed to identify, model, and describe mathematical functions in daily life. The lesson was taught in three classrooms of 24 students, during four sessions of two hours. Students explored linear and quadratic functions, solved equations of three variables, developed limit concepts and applied derivatives. They experimented with pendulums and objects in free-falling, sliding down a ramp and in parabolic trajectories. They also used parachutes, water jets, resistive electrical circuits and solar cookers. All measurements were adjusted to functions of various types and the students interpreted the coefficients. Robot cars were used to learn about angular velocity and limits.

In an entrance survey, $90 \%$ of the students said they did not consider mathematics to be meaningful or useful. In the exit survey, $25 \%$ of the students said that the math is still confusing, but another $25 \%$ said that the learning session helped them somewhat, and $50 \%$ of the students said their math improved significantly. In general, there was a positive shift towards learning mathematics, the use of technology and the relationship of mathematics with science and engineering.

\section{Results and ongoing work}

A series of prototypes emerged from the workshops. In 2008, at José Pardo y Barreda High School, Chincha, students developed a science kit to teach and learn kinematics, and won a first prize in a national competition and classified to an international science and technology fair. In 2016, at Ramón Castilla High School, Pucyura, Cusco, students developed a car counter and a traffic light controller for a dangerous road. In 2017, high school students from Chucuito, Puno, designed an electronic cane to help blind people. This project was classified among ten finalists in a Latin American STEM contest.

Currently, a project-based learning and research-based learning curriculum for the Peruvian high school is being developed. In addition to the basic EECS concepts and applications, the curriculum introduces artificial intelligence, machine learning, 
entrepreneurship and real-time systems, as well as applications in chemistry, biology and medicine. Special attention is given to renewable energy problems since Peru has many regions with hydraulic, wind and solar resources.

The work in progress includes the application of reinforcement learning for formative evaluation, and deep learning for identifying group and individual learning patterns.

\section{Conclusions}

A teaching and learning tool, methods and cases were presented to involve students in STEM through the development of EECS projects.

In the Peruvian context, science labs and engineering workshops in out-of-school settings are the most viable ways of developing projects and involving students in STEM. However, many improvements and teamwork are needed for long-term work.

\section{References}

[1] National Research Council, How People Learn: Brain, Mind, Experience, and School: Expanded Edition, The National Academies Press, Washington, DC, 2000.

[2] National Research Council, How Students Learn: History, Mathematics, and Science in the Classroom, The National Academies Press, Washington, DC, 2005.

[3] OECD, PISA 2015 Results in Focus, 2018.

[4] A. Miguel de Priego, "A Builder and Simulator Program with Interactive Virtual Environments for the Discovery and Design of Logic Digital Circuits", 43rd Annual Frontiers in Education Conference, Oklahoma, 2013.

[5] A. Miguel de Priego, "Out-of-School STEM Education and Project-Based Learning with Emphasis in Electrical Engineering and Computer Science for Peruvian High School Students", WEEF \& GEDC, Seoul, 2016.

[6] A. Miguel de Priego, "Workshop: Teaching and Learning Electrical Engineering and Computer Science in High School with a STEM Approach", 21th International Conference on Interactive Collaborative Learning, Kos, Greece, 2018.

[7] A. Miguel de Priego, "A Framework for K-12 Engineering Education at Low Budget Institutions", Engineering Leaders Conference on Engineering Education, Doha, 2014.

[8] National Research Council, A Framework for K-12 Science Education: Practices, Crosscutting Concepts, and Core Ideas, The National Academies Press, Washington, DC, 2012.

[9] National Research Council, Next Generation Science Standards: For States, By States, The National Academies Press, Washington, DC, 2013.

[10] OECD, PISA 2015 Assessment and Analytical Framework: Science, Reading, Mathematic, Financial Literacy and Collaborative Problem Solving, PISA, OECD Publishing, Paris, 2017. 